Supplementary data for: Formation and Stability of Mononuclear and Dinuclear Eu(III) Complexes and Their Catalytic Reactivity Toward Cleavage of an RNA analog.

Erik R. Farquhar, John P. Richard* and Janet R. Morrow*

Department of Chemistry, University at Buffalo, State University of New York, Amherst, NY

14260-3000. EMAIL: jmorrow@ buffalo.edu; jrichard@ buffalo.edu 


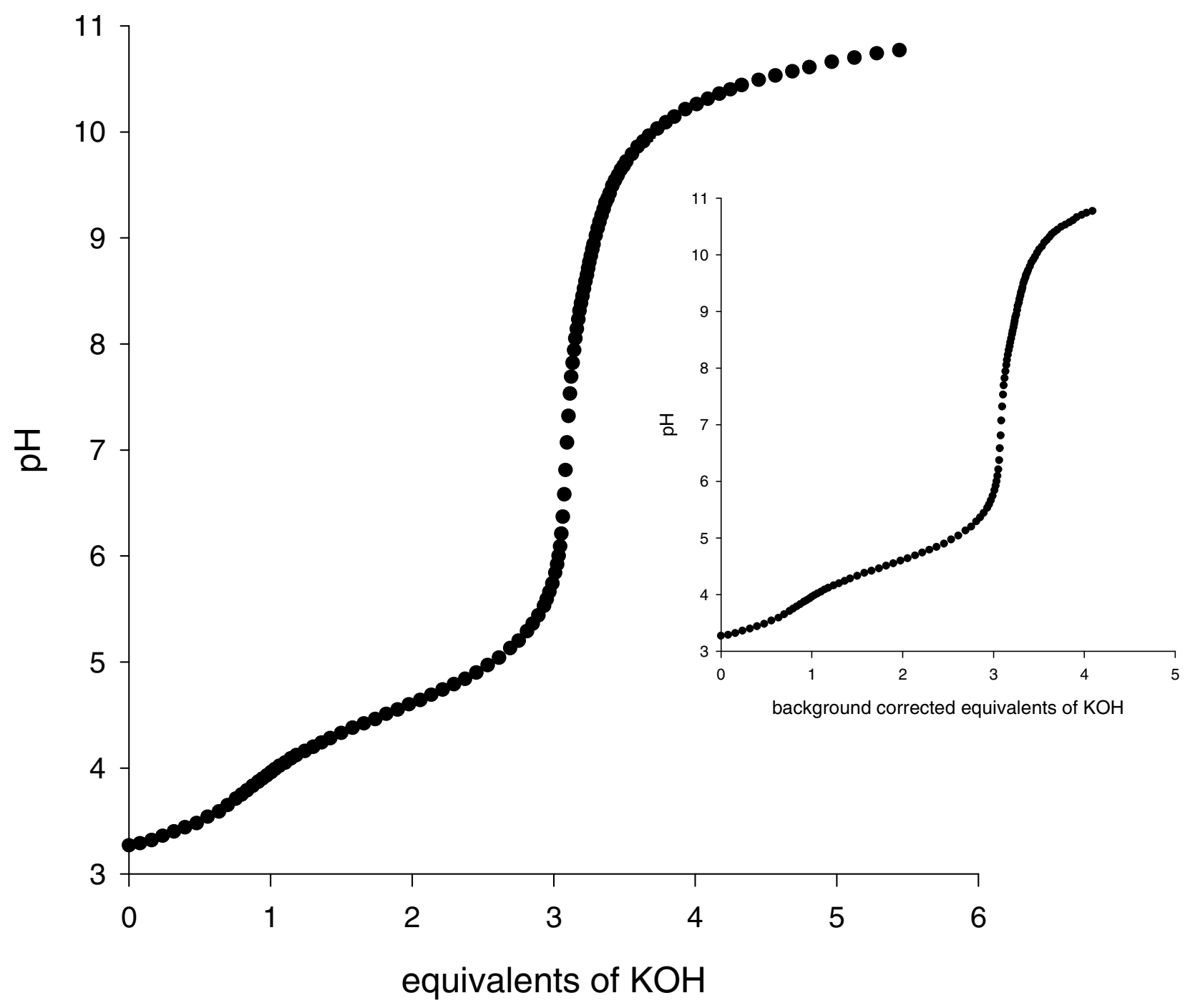

Figure S1. Typical pH-potentiometric titration curve of $1.00 \mathrm{mM} \mathrm{L4}$ and $1.00 \mathrm{mM} \mathrm{EuCl}_{3}$ under conditions of $25.0^{\circ} \mathrm{C}$ and $I=0.10 \mathrm{M}(\mathrm{KCl})$. Inset shows the potentiometric titration curve corrected for background ionization of water at $25.0^{\circ} \mathrm{C}$ and $I=0.10 \mathrm{M}(\mathrm{KCl})$ to clarify the amount of base consumed at alkaline $\mathrm{pH}$ by $\mathrm{Eu}(\mathrm{III})$ (L4) equilibria. 
Scheme S1a. Equilibria and overall formation constants for a scheme involving dimer formation.

$$
\begin{aligned}
& \mathrm{Eu}^{3+}+\mathbf{L 4} \leftrightarrow[\mathrm{Eu}(\mathbf{L} \mathbf{4})]^{+} \\
& \boldsymbol{\beta}_{\mathbf{1 1 0}}=\frac{\left[\mathbf{E u}(\mathbf{L 4})^{+}\right]}{\left[\mathbf{E \mathbf { u } ^ { 3 + }}\right][\mathbf{L 4}]} \quad \log \boldsymbol{\beta}_{\mathbf{1 1 0}}=11.85 \pm 0.02 \\
& 2 \mathrm{Eu}^{3+}+2 \mathbf{L} \mathbf{4}+\mathrm{OH}^{-} \leftrightarrow\left[\mathrm{Eu}_{2}(\mathbf{L} \mathbf{4})_{2}(\mathrm{OH})\right]^{+} \\
& \boldsymbol{\beta}_{22-1}=\frac{\left[\mathbf{E u}_{2}(\mathbf{L 4})_{2}(\mathbf{O H})^{+}\right]}{\left[\mathbf{E u}^{3+}\right]^{\mathbf{2}}[\mathbf{L 4}]^{2}\left[\mathbf{O H}^{-}\right]} \quad \log \boldsymbol{\beta}_{22-1}=17.43 \pm 0.05 \\
& 2 \mathrm{Eu}^{3+}+2 \mathbf{L 4}+2 \mathrm{OH}^{-} \leftrightarrow \mathrm{Eu}_{2}(\mathbf{L 1})_{2}\left(\mathrm{OH}^{-}\right)_{2} \\
& \beta_{22-2}=\frac{\left[\mathbf{E u}_{2}(\mathbf{L 4})_{2}(\mathbf{O H})_{2}\right]}{\left[\mathbf{E u}^{3+}\right]^{2}[\mathbf{L 4}]^{2}\left[\mathbf{O H}^{-}\right]^{2}} \quad \log \boldsymbol{\beta}_{22-2}=6.78 \pm 0.07
\end{aligned}
$$

Scheme S1b. Equilibria for a scheme involving monomer deprotonation.

$$
\begin{aligned}
& \mathrm{Eu}^{3+}+\mathbf{L 4} \leftrightarrow[\mathrm{Eu}(\mathbf{L 4})]^{+} \\
& \mathrm{Eu}(\mathbf{L 4})^{+}+\mathrm{OH}^{-} \leftrightarrow[\mathrm{Eu}(\mathbf{L} \mathbf{4})(\mathrm{OH})]
\end{aligned}
$$

Scheme S1c Stepwise formation constants for equilibria in Scheme 1a

$$
\begin{aligned}
& \mathrm{Eu}^{3+}+\mathbf{L 4} \leftrightarrow[\mathrm{Eu}(\mathbf{L} \mathbf{4})]^{+} \\
& \boldsymbol{K}_{\mathrm{EuL}}=\frac{\left[\mathbf{E u}(\mathbf{L 4})^{+}\right]}{\left[\mathbf{E u}^{3+}\right][\mathbf{L 4}]} \quad \log \boldsymbol{K}_{\mathbf{E u L}}=11.85 \pm 0.06 \\
& 2 \mathrm{Eu}(\mathbf{L 4})^{+}+\mathrm{OH}^{-} \leftrightarrow\left[\mathrm{Eu}_{2}(\mathbf{L 4})_{2}(\mathrm{OH})\right]^{+} \\
& K_{\mathbf{D}}=\frac{\left[\mathbf{E u}_{\mathbf{2}}(\mathbf{L 4})_{2}(\mathbf{O H})^{+}\right]}{\left[\mathbf{E u}(\mathbf{L 4})^{+}\right]^{2}\left[\mathbf{O H}^{-}\right]} \quad \log K_{\mathbf{D}}=7.50 \pm 0.02 \\
& {\left[\mathrm{Eu}_{2}(\mathbf{L 4})_{2}(\mathrm{OH})\right]^{+}+\mathrm{OH}^{-} \leftrightarrow\left[\mathrm{Eu}_{2}(\mathbf{L 4})_{2}(\mathrm{OH})_{2}\right]} \\
& K_{\mathrm{a}}=\frac{\left[\mathbf{E u}_{\mathbf{2}}(\mathbf{L 4})_{2}(\mathbf{O H})_{2}\right]}{\left[\mathbf{E u}_{\mathbf{2}}(\mathbf{L 4})_{2}(\mathbf{O H})^{+}\right]\left[\mathbf{O H}^{-}\right]} \quad \log \boldsymbol{K}_{\mathrm{a}}=10.65 \pm 0.01
\end{aligned}
$$




\section{Scheme S2}
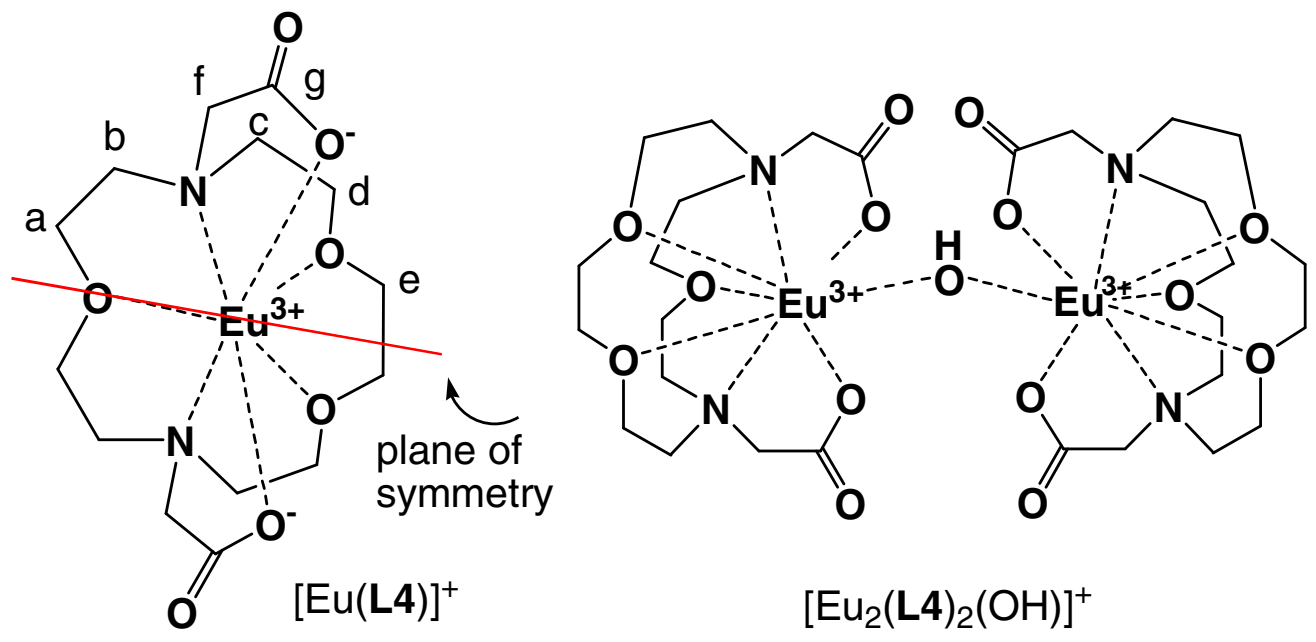

Seven distinct ${ }^{13} \mathrm{C}$ NMR resonances are observed for solutions containing $8.0 \mathrm{mM} \mathrm{L4}$ and $\mathrm{EuCl}_{3}$ at $\mathrm{pD} 6.4\left(I=0.10 \mathrm{M}(\mathrm{KCl})\right.$, conditions that favor mononuclear $[\mathbf{E u}(\mathbf{L 4})]^{+}$as the predominant species (Figure 2, complexes shown without water ligands for simplicity). The macrocyclic complex is anticipated to have fourteen ${ }^{13} \mathrm{C}$ NMR resonances because the ethylene group conformation gives rise to a ruffled macrocyclic ring. That only seven are observed suggests that either the fourteen ${ }^{13} \mathrm{C}$ NMR resonances are not resolved or that there is a fluxional process in solution that interconverts pairs of distinct carbons in the macrocyclic ligand giving rise to an apparent plane of symmetry (see above). Unfortunately, no comparison could be made to the ${ }^{13} \mathrm{C}$ NMR spectra of the dimeric $\left[\mathbf{E \mathbf { u } _ { 2 }}(\mathbf{L 4})_{2}(\mathbf{O H})\right]^{+}$complex because of the coexistence of the two dimeric species shown in Scheme 1 at the high concentrations needed for these experiments.

Ten ${ }^{1} \mathrm{H}$ NMR resonances are observed in solutions containing $1.0 \mathrm{mM} \mathrm{EuCl}_{3}$ and $1.0 \mathrm{mM}$ $\mathbf{L 4}$ at pD $6.4(I=0.10 \mathrm{M}(\mathrm{KCl}))$, conditions that favor the mononuclear species $[\mathbf{E u}(\mathbf{L 4})]^{+}$. The integration ratios demonstrate eight distinct non-overlapping resonances and two sets of two 
overlapping resonances for a total of twelve protons. The lower than anticipated number of ${ }^{1} \mathrm{H}$ NMR resonances is consistent with that observed in the ${ }^{13} \mathrm{C}$ NMR spectra suggesting a higher than expected symmetry.

As the $\mathrm{pD}$ is increased to 10.4 , the original low $\mathrm{pH}$ resonances decrease in intensity, and a set of eleven new resonances (Figure 3 ) appear over a chemical shift range of +13 ppm to -15 ppm, suggesting that there are two distinct Eu(III) species in slow exchange on the ${ }^{1} \mathrm{H}$ NMR timescale. The greater chemical shift dispersion observed for the high $\mathrm{pH}$ complex identifies this species as a dimeric complex because two Eu(III) centers typically give rise to a larger dipolar shift. Assuming there is a symmetry plane in the dimeric complex that passes through the $\mathrm{Eu}(\mathrm{III})-\mathrm{OH}-\mathrm{Eu}(\mathrm{III})$ bridge and bisects the macrocyclic ligand, analogous to the monomeric complex, there are 12 possible proton environments, corresponding to the eleven observed here with two of the resonances overlapping. Integration of these resonances gives relative percentages of monomer and dimer in the NMR spectroscopy experiments that are qualitatively similar to that predicted by $\mathrm{pH}$-potentiometric titrations after the expected ionization differences of the complexes in $\mathrm{D}_{2} \mathrm{O}$ compared to $\mathrm{H}_{2} \mathrm{O}$ are taken into account. For example, if we assume that the ionization of $\left[\mathbf{E u}(\mathbf{L 4})\left(\mathbf{O D}_{2}\right)_{2}\right]^{+}$occurs at approximately $0.4 \mathrm{pL}$ units $(\mathrm{L}=\mathrm{H}, \mathrm{D})$ higher than for $\left[\mathbf{E u}(\mathbf{L 4})\left(\mathbf{O H}_{2}\right)_{2}\right]^{+}$, the percent of complex present as $\left[\mathbf{E u} \mathbf{u}_{2}(\mathbf{L 4})_{2}(\mathbf{O L})(\mathbf{O L})_{2}\right]^{+}$from NMR studies and pH-potentiometry is similar. By NMR spectroscopic studies 49\% at pD 9.5 and $69 \%$ at $\mathrm{pD} 10.4$ of the species are present as dimer compared to $43 \%$ at $\mathrm{pH} 9.1$ and $62 \%$ at $\mathrm{pH} 10.0$ dimer by $\mathrm{pH}-$ potentiometric measurements: 


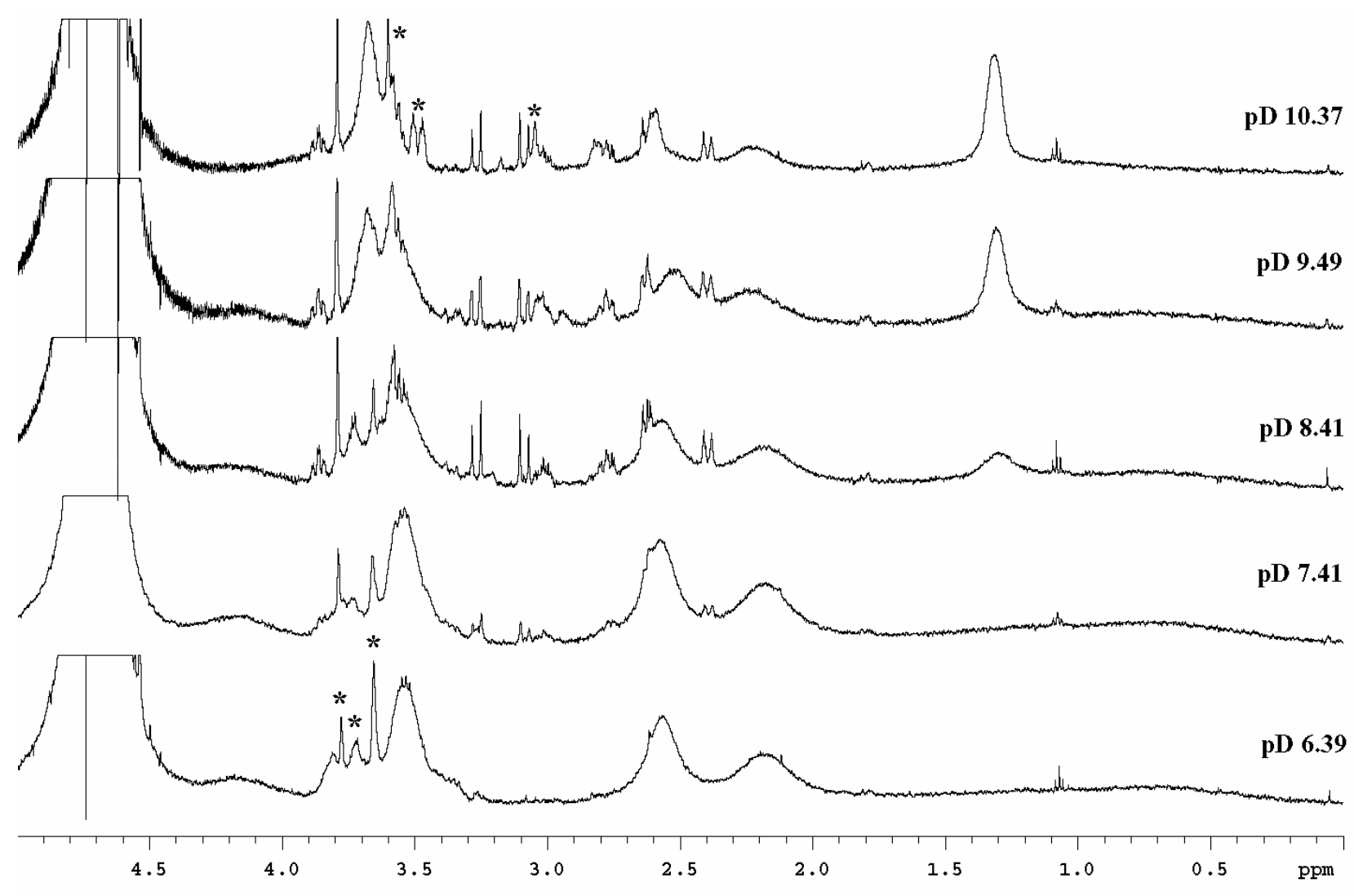

Figure S3. Expansion of the region between $0 \mathrm{ppm}$ and $5 \mathrm{ppm}$ for the $\mathrm{pD}$ titration of $1.00 \mathrm{mM}$ $\operatorname{Eu}(\mathbf{L 4})(I=0.10 \mathrm{M}(\mathrm{KCl}))$. Peaks labeled with $*$ are attributable to the free ligand, and the triplet at $1.07 \mathrm{ppm}$ is due to ethanol. The remaining sharp resonances (comprising 1 to 2 percent of all $\mathbf{L} 4$ complexes) are assigned to $\mathbf{C a}(\mathbf{L} 4)$. This assignment was confirmed by the results of a spiking experiment at pD 10.33 (Figure S4), in which a sample was prepared with $0.25 \mathrm{mM}$ $\mathbf{C a}(\mathbf{L 4})$ and $0.75 \mathrm{mM}[\mathbf{E u}(\mathbf{L} 4)]^{+}$. No peaks besides those clearly attributable to either $[\mathbf{E u}(\mathbf{L} 4)]^{+}$ or $\mathbf{C a}(\mathbf{L 4})$ are present. 


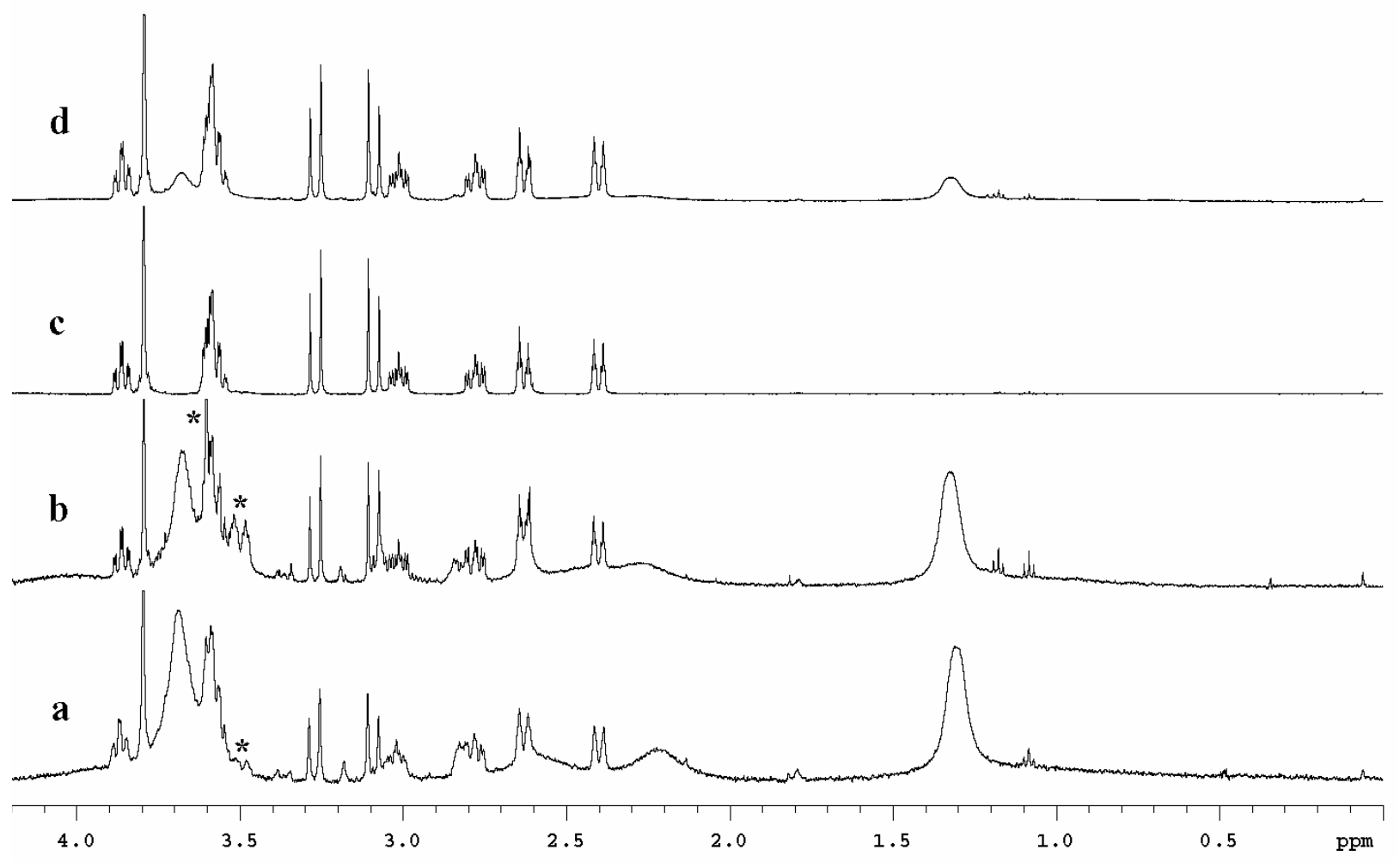

Figure S4. ${ }^{1} \mathrm{H}$ NMR spectra at $\mathrm{pD} 10.28$ and $I=0.10 \mathrm{M}(\mathrm{KCl})$ of (a) $1.00 \mathrm{mM} \mathrm{EuCl}_{3}$, and $\mathbf{L} \mathbf{4}$ (b) $1.00 \mathrm{mM} \mathrm{Eu}\left(\mathrm{CF}_{3} \mathrm{SO}_{3}\right)_{3}$ and $\mathbf{L 4}(\mathbf{c}) 1.00 \mathrm{mM} \mathrm{Ca}(\mathbf{L} 4)$ from $\mathrm{CaCl}_{2}$, and (d) $0.75 \mathrm{mM} \mathrm{Eu}(\mathbf{L} 4)_{\mathrm{T}}$ and $0.25 \mathrm{mM} \mathrm{Ca(L4)}$ at $\mathrm{pD} 10.33$. Note that different sources of high purity $\mathrm{Eu}(\mathrm{III})$ salts $(>99.9 \%)$ give similar NMR spectra in this region. The source of the $\mathrm{Ca}^{2+}$ is most likely water and/or glassware. 
Scheme S3

$\left[\mathbf{E u}(\mathbf{L 4})\left(\mathrm{OH}_{2}\right)_{2}\right]^{+\stackrel{K_{\mathrm{a}}}{\rightleftharpoons}}\left[\operatorname{Eu}(\mathbf{L 4})\left(\mathrm{OH}_{2}\right)(\mathrm{OH})\right] \stackrel{k_{\text {Eumax }}[\mathrm{HpPNP}]}{\longrightarrow}$ products

Eq. (S1) $\quad k_{\text {Eumax }}=\left(\left(k_{\text {Mon }}\right)_{\text {app }} K_{\mathrm{a}}\right) /\left(K_{\mathrm{a}}+\left[\mathrm{H}^{+}\right]\right)$

Values for $\left(k_{M o n}\right)_{a p p}$ are taken from Table 2. Fittting of the data in Figure 6 (mononuclear complex) to Eq. S1 gives $K_{a}=1.0 \times 10^{-8}$ and $k_{\text {Eumax }}=0.030 \mathrm{M}^{-1} \mathrm{~s}^{-1}$ 


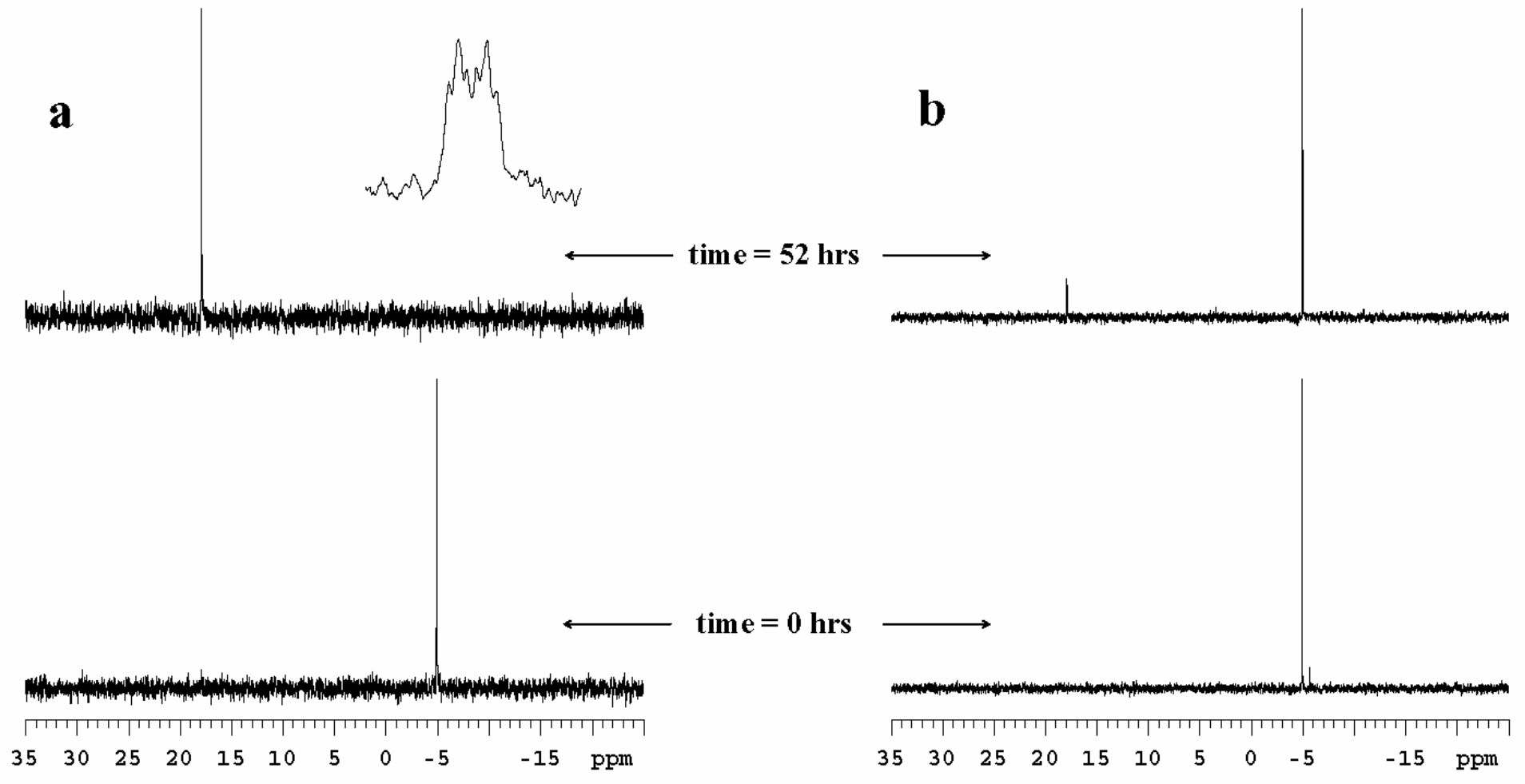

Figure S5. ${ }^{31} \mathrm{P}$ NMR spectra recorded at the start of the reaction and after $52 \mathrm{hrs}$ for the reaction of $2.0 \mathrm{mM}$ HpPNP (a) with $0.5 \mathrm{mM}[\mathbf{E u}(\mathbf{L 4})]_{\mathrm{T}}$ and (b) in the absence of catalyst at $25.0^{\circ} \mathrm{C}, I=0.10 \mathrm{M}(\mathrm{KCl})$, and $20 \mathrm{mM}$ CHES buffer at $\mathrm{pH} 9.10$. The inset is the ${ }^{1} \mathrm{H}-$ coupled ${ }^{31}$ P NMR spectrum of the HpPNP transesterification product in the presence of $[\mathbf{E u}(\mathbf{L 4})]$ catalyst. This ${ }^{31} \mathrm{P}$ NMR resonance of the product corresponds to that of the cyclic phosphate ester. 